\title{
Development and Implementation of an Undergraduate Course on Smart Grids
}

\section{Dr. Radian G. Belu, University of Alaska, Anchorage}

Dr. Radian Belu is Associate Professor within Electrical Engineering Department, University of Alaska Anchorage, USA. He is holding one PhD in power engineering and other one in physics. Before joining to University of Alaska Anchorage Dr. Belu hold faculty, research and industry positions at universities and research institutes in Romania, Canada and United States. He also worked for several years in industry as project manager, senior engineer and consultant. He has taught and developed undergraduate and graduate courses in power electronics, power systems, renewable energy, smart grids, control, electric machines, instrumentation, radar and remote sensing, numerical methods, space and atmosphere physics, and applied physics. His research interests included power system stability, control and protection, renewable energy system analysis, assessment and design, smart microgrids, power electronics and electric machines for non-conventional energy conversion, remote sensing, wave and turbulence, numerical modeling, electromagnetic compatibility and engineering education. During his career Dr. Belu published ten book chapters, several papers in referred journals and in conference proceedings in his areas of the research interests. He has also been PI or Co-PI for various research projects United States and abroad in power systems analysis and protection, load and energy demand forecasting, renewable energy, microgrids, wave and turbulence, radar and remote sensing, instrumentation, atmosphere physics, electromagnetic compatibility, and engineering education.

\section{Prof. Lucian Ionel Cioca, Lucian Blaga University of Sibiu}

Lucian Ionel CIOCA received the M.Sc. in Machine Tools (1993) and B.Sc. in Occupational Safety, Health and Work Relations Management (2010). In 2002, he becomes Dr. Eng. (Ph.D degree) of Petrosani University, Romania and now he is professor at "Lucian Blaga" University of Sibiu - Romania, Faculty of Engineering, Department of Industrial Engineering and Management, Romania. His teaching subjects are Ergonomics, Management, Human Resources Management, Occupational Health and Safety Management, Production Systems Engineering. His research fields of interest are linked with the impact of the knowledge based society upon the social / human dynamics / evolution and the production systems. He regularly publishes and participates on international scientific conferences. Lucian Cioca is the Administrator of the LBUS Department of Consulting, Training and Lifelong Learning, Doctoral Advisor in Engineering and Management, Member of the National Council for Attestation of Academic Titles, Diplomas and Certificates, evaluator ARACIS (The Romanian Agency for Quality Assurance in Higher Education), and other (email: lucian.cioca@ulbsibiu). 


\title{
Development and Implementation of an Undergraduate Course on Smart Grids
}

\begin{abstract}
The "Smart Grid" concept proposes to move the power system technology to the next level to improve efficiency, reliability, and environmental sustainability. In order to maintain a reliable, robust and secure electricity infrastructure that can meet further demand growth, the electrical grid is evolving toward the future power system, the smart grid, through the increased use of information technology, computing, advanced control, distributed generation, renewable energy, demand-side response, intelligent metering and monitoring, and deployment of the intelligent technologies. Smart grid (SG) concept is also driving many of the current changes in engineering curricula. Present power industry trends, the aging assets and workforce, renewable energy integration, all in the smart grid background, making the discussions around what is expected of the future utility workforce even more complicated. Educators and industry personnel are trying to figure out the answers to these questions and common themes are slowly emerging as there is no definitive consensus on the expected future workforce needs, workforce development and training in the SG inter-disciplinary areas. Existing educational programs and curricula must fit the needs of students, faculty and employers for a workforce that is capable of deploying and operating the smart grid technologies, including measurements, monitoring, communication, computing, control and power electronics make the required education and training even more challenging. Power system operation, analysis and design need to be formulated in a way that is understandable by non-power engineers for better SG development and implementation. To train professionals and students in smart grids, a creative curriculum crossing traditional disciplines is needed. For example, students taking advanced courses in power engineering have an electrical engineering background, as do students in the control systems and telecommunications fields. While students interested in communication networks typically have a computer science or engineering background. This divergence results in many challenges for the coeducation of such professionals and students. We are discussing our approach in the design, development and implementation of an undergraduate course, and the associate laboratory on smart grids. Project challenges include the selection of most appropriate course level, content and topics, textbooks, additional learning materials, laboratory experiments, inclusion or not an end-of-semester project, or field trips, etc. Two fundamental issues characterize smart grid education: multidisciplinary education and integrative nature of the smart grid solutions.
\end{abstract}

\section{Introduction}

Equipping engineering students with the skills and knowledge required to be successful global engineers in the 21st century is one of the primary objectives of undergraduate educators. Enabling students to practice self-learning, to find solutions to the real-world design problems that are sustainable to the application requirements and constrains, to have solid and appropriate skills and knowledge, as well as the familiarity of the modern software packages, methods, tools and equipment used in modern industries are major goals of all engineering programs. However, one of the shortcomings of current engineering programs has been the lack of training in skills, knowledge, and tools used in industry that a new graduate needs when entering the workforce in order to rapidly adapt to the work environment and requirements. Smart grid is considered an 
attractive topic in electrical engineering programs, with strong appealing among students, professionals and educators. According to the US Department of Energy "Smart Grid generally refers to a class of technology people are using to bring utility electricity delivery into 21 st century using computer based remote control and automation' ${ }^{1}$. This initiative requires power engineers to have a good understanding of auxiliary fields like controls, information technology (IT), and communication networks, while being experts in the basic operations of the future power systems. There is a great need in the power industry and not only for such cross-trained graduates and professionals to meet challenges and needs in the power gird modernization ${ }^{2-6}$. Keeping in mind that the advent of telecommunication, computing, and monitoring technologies, new approaches have been possible in the electrical power systems. Many grid operations are vitally dependent on monitoring, collecting, processing transmitting and sharing data. Power engineering has commoditized the electric network and computation solutions, finding the offthe-shelves products that fit the needs, by defining a logical mapping between desired functions and communication standards. To train students in smart grids require a creative curriculum that crosses traditional engineering divisions ${ }^{3,7-12}$. For example, students taking advanced courses in the power systems area traditionally have an electrical engineering background as do students in the control and telecommunications fields. However, students involved in computer networking and communications require a computer science or computer engineering background. This divergence results in many challenges in co-education of such professionals and students.

Our course will provide students with knowledge of the SG fundamentals, analysis, topics, its structure, major components, operation and management. The undergraduate course on smart grids is stacked with a graduate course to make the course available to graduate students and professionals. The course introduce students to the basic concepts of power systems along with the inherent elements of computational intelligence, monitoring, communication technology, infrastructure, and decision support systems. The automation and components needed to ensure that the SG guarantees adaptability and capabilities are discussed in depth, the interoperability of renewable energy sources and components are presented and discussed, ensuring minimum changes in the existing power system legacy. Standards needed for designing new SG devices and products are also included. This paper presents the thought process behind the establishment and implementation of a stacked upper division undergraduate and graduate level courses on smart grid fundamentals planned to be offered at the authors' institutions. The course is also intended for professionals already working in power and energy industries in our region. Specific aspects discussed are the course outline, objectives and goals, selection of multi-disciplinary topics for this course, challenges envisioned, and lessons learned during this endeavor.

\section{Course Content and Structure}

The course structure and the selection of topics were based primarily on two considerations. First one was ensuring electrical engineering and power systems students are exposed to basic techniques from computational intelligence, IT, communication techniques, and computer networking, and graduate students and professionals understood the modern power grid, power system components and its fundamentals ${ }^{11-14}$. The second consideration was ensuring the instructor have adequate expertise on the chosen topics. Additional consideration of adding topics in control theory and applications, and environmental and economic issues are presented. Power system topics emphasize what the authors feel are emerging and important research 
topics, with a concentration in the area of power distribution. Topics in the networking, monitoring and communication emphasize on requirements, enabling of consumer participation in energy delivery, and information security and privacy. These topics in the networking are in emerging research areas of the computer science and deemed to be of critical importance in the smart grid realization. The topics on environmental and economic issues add a focus on sustainable energy solutions and expose the students to the expected SG impacts. To provide a third dimension apart from power systems and computer networks, topics in control system covered have direct applications towards modernizing and implementation of the power grid.

The basic power system analysis tools are natural bridges between the physical world of power transfer, and monitoring, communications and energy management. This statement is guiding our SG course design and implementation. The course is starting with a review of the basics of circuit theory and power system basics critical for the understanding of power system operation and management, followed by the power flow equations, the interconnection of transmission lines and devices into the high, medium and low voltage power networks, with their peculiarities, requirements and constrains. Next the energy management, economic dispatch of power and the description how the energy market works are discussed and presented. Part of this description will focus on the challenge of balancing the supply and demand, followed by the description of alternative physical layers to collect and communicate information, considering wireless, power line carriers, optical fibers, etc. Course materials are prepared from a cross-disciplinary perspective encompassing communications, controls, renewable energy, energy conservation, sustainability, and power system fundamentals. Being a new area there are few undergraduate textbooks on smart grids. It is the authors believe that the course materials developed during our project can eventually form the basis for developing an undergraduate textbook on smart grids and also lay out the foundation for introducing an undergraduate course in the area of systems engineering focused on smart grids. In the stacked graduate course, students are required to apply their skills and learn new techniques in the SG areas with additional requirements and topics. An alternative course development approach might to start top-down by introducing the smart grid concepts earlier and discussing and presenting the other topics in this context.

\subsection{Course Description}

The course provides students with working knowledge of SG fundamentals, design, analysis, and development, offering an introduction to the fundamental concepts of modern power systems along with the inherent elements of control, computing, communication technology and decision support, automation and monitoring techniques ensuring the SG guarantees the adaptability and capability of handling new power systems and components, the interoperability with renewable energy, distributed generation and smart loads. The power system topics are emphasizing on what the authors feel are also emerging and important research topics, with a fair concentration in the area of power distribution systems. The computer networking and communication topics are emphasizing on communication requirements, enabling of consumer participation in energy delivery, and information security and privacy. These topics in the networking are in emerging research areas of the computer science community and deemed to be of great importance in realizing the smart grid vision. The environmental and economic topics focus on sustainable energy solutions and expose the students to issues related to the SG expected impacts. 


\subsection{Course Level Justification}

Our electrical and power engineering programs have been carefully designed to prepare students for the profession of electrical engineering through study, experience and practice, and to became professionals and business leaders in our state with objectives, such as: electrical engineering graduates with the training and skills to enter the job market or to continue their education by attending graduate school, become business leaders and entrepreneurs, engaging in life-long learning, at the highest of ethical behavior and social responsibility. The emerging clean-energy smart grid environment in the electric power sector has necessitated that related educational programs, course or laboratory development and implementation evolve to meet the needs of students, faculty, and employers alike. In order to prepare the future power engineering professionals to meet the challenges ahead in the power industry, a new curriculum must be developed that includes core power engineering principals coupled with emerging aspects of smart grid technologies, green electricity generation, or clean energy integration. SG initiative not only requires power engineers to have a better understanding of auxiliary fields like signal processing, controls, information technology, and communication networks, but also needs experts in the auxiliary fields to understand the basic operations of power systems. These include topics form energy storage technologies, power electronics at the transmission and distribution levels, networked control systems, automation, renewable and alternative energy systems integration, system optimization, real-time control, and other related topics. In addition, one must take also into account significant input from industry constituents engaged in the manufacturing, implementation, operation, and maintenance of the new smart grid technologies and systems. There is a great need in industry for such cross-trained professionals to meet challenges in modernizing the power grid. This course involves understanding, analysis, and modeling of the future power grid, working knowledge of SG fundamentals, design, analysis, and development, from the fundamental concepts of power systems to the inherent elements of computational intelligence, advanced metering and monitoring infrastructure, communication technology, energy management and decision support system. The intended audience for this course would be from the following three groups: (i) power and electrical engineering students interested in grid automation, communication, monitoring, renewable energy integration, or impacts of energy storage on power distribution, (ii) computer sciences and engineering students interested in a career where their networking skills are applied in the power systems, and (iii) control engineering students interested in developing control solutions for power system applications.

Designing the course execution to keep students from diverse backgrounds engaged can be challenge. As a result it was decided to start off with basic introductory lectures in the two major thrust areas before advanced topics are covered in either of them. This is expected to provide an early common platform for all students to subsequently understand and appreciate advanced topics. The power systems part starts with an introduction/refresher that included basic concepts like circuit theory for computer networking students who may be out of touch. Basic computer networking and internet concepts were covered, for professional or students with no solid background in these areas. All course assignments and projects are assigned as groups that were to include one student from each of the major backgrounds like power systems, computer networks, and control systems. This enabled one student, well-versed in the area under consideration, to be the lead in an area-specific assignment who helped students from other backgrounds catch up. For projects, this enabled the formulation of multi-disciplinary problems 
that required students from diverse backgrounds to join together in proceeding towards a solution. By identifying the emerging clean-energy smart grid of the electric power sector as an area of need for educational development, models for new curriculum development are therefore required. The smart grid can be defined as 'the implementation of various enabling power system automation, communication, protection, and control technologies that will allow real-time interoperability between end-users and energy providers, in order to enhance efficiency in utilization decision-making based on resource availability and economics.

\subsection{Course Topics and Outline}

This course is intended for senior undergraduate students but it is also open to senior graduate students and industry professionals. There is no official pre-requisite at the time of enrolment. However, basic knowledge of power systems, basic knowledge of computer and communications networks, and some background in probability and random variables, linear algebra, and convex optimization will be helpful. Major course topics included in our SG course are:

1. Introduction to Power System Operation and Management

2. Basics of Power Systems, Load and Generation, Power Flow Analysis, Economic Dispatch and Unit Commitment

3. Smart Grid Structure, Architecture and Operation

4. Key Characteristics of Smart Grid; Smart Grid Models, Key Functions of a Smart Grid

5. Smart Grid Elements, Control Elements and Applications Layers

6. Smart Grid Monitoring, Metering and Communication Infrastructure:

7. Demand Management, Demand Side Ancillary Services;

8. Smart Grid Energy Management

9. Renewable Generation and Distributed Generation in Smart Grid

10. Microgrid Concepts, Architecture and Management

11. Microgrid and Power Grid Fault Studies:

12. Security, Economics and Market Operations

13. Policy and Economic Drives of Smart Grid, Standards and Cyber-security

Due to the interdisciplinary and novelty of the smart grid nature of the topics covered in this course are hardly to find in a single textbook. The authors decided to develop a complete set of lecture notes and tutorials and provide the full student access via course website. Additional references and recommended textbooks ${ }^{15-19}$ were included in the course syllabus with special requirements for graduate students and professionals taking the course. However, the authors intended to publish during this or next year a textbook on Fundamentals on Smart Grids closer to the course content. All course materials will be available to the students on the course website.

\section{Course Instructional Goals and Student Learning Outcomes}

1. The course presents engineering techniques of the future power system, smart grid and microgrid concepts, components, structure and architecture; this course will examine not just the smart grid technologies, but the transformational impacts of the smart grid on the industry. 
2. Introduce communication, networking, and sensing technologies involved with the smart grid; computational techniques involved with the smart grid (decision support tools and optimization)

3. Motivate and explain tools and techniques used in power systems and smart grid

4. Introduce the smart grid modeling for large-scale power networks, power flow analysis; optimal dispatch, energy management, standards, concepts and principles of smart grid communications, metering, monitoring and protection technologies and techniques, and computational tools used in smart grids.

Among student learning outcomes are: Student Learning Outcomes. Upon successful completion of this course students will be able to:

1. Analyze, simulate and model smart grid components, their characteristics and performance

2. Understand of various aspects of smart grid, architecture, components, management technologies and applications

3. Understand fundamental structure and elements of smart grid standards, interoperability and cybersecurity

4. Know the basic types of electric utilities in the US; for each type of utility, be able to describe the business model, governance structure, and how the utility is regulated and managed.

Student assessment and evaluation is proposed to be performed through, assignments, exams, case studies and projects with additional requirements for graduate students and professionals taking the course. All assignments, home-works and solutions, as well as power point presentations, additional course materials are planned to be posted on the course website.

\section{Projects and Future Laboratory}

Traditionally, in the development of engineering education the key objectives are to enable the teachers to convey knowledge and insight to the students. The main element is the lecture, in which the teacher explains, gives examples, shows calculations, discusses physical principles or mathematical derivations, etc. However, the laboratory, experiments and projects are an integral part of any engineering, science or technology educational program and their purpose is bringing the students closer to real situations of the area of studies ${ }^{20-22}$. Laboratories to study power system issues have always been deemed important by educators. Laboratory practices reveal that many instructors are moving away from large machines and in some cases are even replacing machines labs with either power systems experiments or power systems simulations. Comprehensive literature reviews shown on laboratory and testbeds on smart grids, microgrids, renewable energy and distributed generation infrastructures exist or underway to be developed, for both research and education. At our university we are in process of developing and implementing an integrated laboratory on energy conversion, power electronics, smart grids, renewable energy and microgrids ${ }^{21-27}$. Major equipment and devices include Real Time Digital Simulator (RTDS), power electronics and energy conversion modules, renewable energy emulators, and a microgrid testbed. RTDS is built in RSCAD user interface software in real time, working on the parallel processing technology of digital signal processors and executes the program developed on its processors ${ }^{23-25}$. The RTDS not only calculates and shows the electrical output values in the runtime software, but also produces scaled output signals (digital as well as 
analog) through the output interface cards incorporated into its system. It is an ideal learning tool to illustrate simulation techniques, power system dynamics and operation, allowing students to gain experience with the real world measurements, protection and control equipment which can be connected to the RTDS Simulator. It can be used to conduct closed-loop testing of physical devices such as protection equipment and control equipment, including IEC 61850 devices, to perform analytical system studies or to educate power system operators, engineers and students. Students can effectively interact with an operating power system modeled by the simulator, gain real and current industrial hands-on experience. The RTDS Simulator provides students with hands-on illustrative tools helping them bridge the gap between theory and practical operation of a power system. Moreover, the simulator has functions and capabilities of advanced metering, monitoring and control of future smart grids, opening new areas for education, training and research for our students. The virtual renewable energy experimental setting consists of five emulators facilitating students' acquisition of deep insight into the complex and dynamic interactions of system parameters. A high degree of interactivity should be provided and the students should have the possibility to investigate the causal relation between different states of the system under study. It should be accessible, independent of time and place. Moreover, the renewable energy source models are posted with their simulation under different operating conditions. It is expected that students will be motivated to study and analyze these systems in more detail, so as to become skilled in designing and component layout of such systems. The renewable energy sources to be developed for this virtual and remote access laboratory are as follows: 1) Wind Turbine Emulator; 2) PV System Emulator; 3) Fuel Cell Simulator; 4) Solarthermal Emulator and 5) Battery Bank Emulator. Each module, with the exception of first one is divided into three parts: basic principles, system technology, and a laboratory manual. Finally the renewable energy emulators, associated power electronics and control interfaces are planned to be integrated into a microgrid testbed.

Through this laboratory experiments, course projects and case studies, our students are exposed to tools, software and equipment used in the present power and energy industries, including those utilized in the future smart grid. We believe that exposing our students to this complex power system training equipment will increase the likelihood of employment opportunities and internships with local or nationwide utilities, power equipment manufacturing and energy companies for our students.

\section{Conclusions and Future Developments}

In this paper, the motivation and process of developing an undergraduate course on smart grid fundamentals has been discussed. With the advent of computing, communication, information technology, power electronics, intelligent control and automatization, the electrical grid is moving rapidly toward the future power system, the smart grids. By establishing a stronger formal education base in the clean-energy smart grid at our university, we consider that not only our program will increase the interests and visibility our students to pursue a power engineering career, but also many power or energy related companies could benefit of this opportunity to train their engineers in future power system areas. Utilities, manufacturers, consultants, government agencies, and in fact all organizations engaged in the electric power and energy sector, would benefit from investing in their employee's futures and overall professional and personnel advancement. The aim of work is to develop, design and implement an undergraduate 
course on SG fundamentals, while providing the students with knowledge, skills, tools and techniques required in future power systems and clean electricity generation. Detailed coverage of course structure, content, topics are presented and discussed in the paper. Lessons learned will be available for interested parties, instructors or researchers, and the feedback are highly appreciated.

\section{References}

1. Smart Grid, Department of Energy, available: http://energy.gov/oe/technology-development/smartgrid

2. S.E. Collier, Ten steps to a smarter grid, IEEE Industry Applications Magazine, Vol. 16(2), pp. 62-68, 2010.

3. P. Sauer, G. Heydt, and V. Vittal, The state of electric power engineering education, IEEE Trans. Power Syst., vol. 19, no. 1, pp. 5-8, Feb. 2004.

4. V.G. Agelidis, The future of power electronics/power engineering education: challenges and opportunities, in Proc. of IEEE Workshop on Power Electronics Education, 2005, p. 1-8.

5. R.G. Belu - Renewable Energy Based Capstone Senior Design Projects for an Undergraduate Engineering Technology Curriculum, 2011 ASEE Conference \& Exposition, June 26 - 29, Vancouver, BC, Canada (CD Proceedings).

6. H. Gharavi and R. Ghafurian, Smart grid: the electric energy system of the future, Proceedings of the IEEE, Vol. 99(6), 2011, p. 917- 921

7. R. Belu, Smart Grid Communication, in Encyclopedia of Energy Engineering \& Technology (Ed Sohail Anwar), Vol. 3, 2014 (28 pages)

8. G.F. Reed, G.F., A Powerful Initiative at Pitt - The University of Pittsburgh Swanson School of Engineering Power \& Energy Initiative: Building Engineering Education and Research Partnerships through Academic- Industry Collaboration, IEEE Power \& Energy Magazine, Vol. 6( 2), March/April, 2008.

9. G.T. Heydt, M. Kezunovic, P.W. Sauer, A. Bose, J.D. McCalley, C. Singh, W.T. Jewell, D.J. Ray, V. Vittal, Professional resources to implement the "smart grid", in Proc. of North American Power Symposium (NAPS), pp. 1-8, 2009.

10. L. Hirst, Transforming engineering education: creating interdisciplinary skills for complex global environments, in Proc. of IEEE Transforming Engineering Education: Creating Interdisciplinary Skills for Complex Global Environments, pp. i-ix, 2010.

11. P.W. Sauer, Educational needs for the "smart grid" workforce, in Proc. of IEEE Power and Energy Soc. General Meeting., p. 1-3, 2010.

12. G.F. Reed, and W.F. Stanchina, Smart grid education models for modern electric power system engineering curriculum, 2010 IEEE Power and Energy Society General Meeting, pp. 1 - 5, 2012, DOI: 10.1109/PES.2010.5589617

13. A., Scaglione, A course on smart grid networks, in Power and Energy Society General Meeting, 2012 IEEE, pp. 1-2, 2012, DOI: 10.1109/PESGM.2012.6345730

14. M. Ilic, Critical Needs for Multi-Disciplinary Approach to Teaching Electric Energy Systems, in the 2014 Innovative Smart Grid Technologies Conference (ISGT), IEEE PES, pp. 1 - 5, 2014, DOI: 10.1109/ISGT.2014.6816462

15. James Momoh, "Smart Grid Fundamentals of Design and Analysis, Wiley, 2012; ISBN 978- 0- 47088939-8

16. A. Keyhani, Design of Smart Power Grid Renewable Energy Systems, Wiley - IEEE Press, 2011, ISBN: 978-0470-627621-7

17. F. P. Sioshansi (ed.), Smart Grid: Integrating Renewable, Distributed \& Efficient Energy, Academic Press/Elsevier, 2012 
18. R. Belu, Microgrid Concepts and Architectures, 2013 (DOI: 10.1081/E-EEE-120048432/29 pages); in Encyclopedia of Energy Engineering \& Technology (Online) (Ed: Dr. Sohail Anwar), Taylor and Francis/CRC Press

19. N. Lidula and A. Rajapakse, Microgrids research: A review of experimental microgrids and test systems, Renew. Sustain. Energy Rev., vol. 15, no. 1, pp. 186-202, Jan. 2011

20. R. G. Belu, R. Chiou, B. Tseng and L. Cioca - Advancing Sustainable Engineering Practice through Education and Undergraduate Research Projects, ASME 2014 International Mechanical Engineering Congress \& Exposition (IMECE2014), November 14-20, 2014, Montreal, Quebec, Canada (CD Proceedings)

21. R.G. Belu, Design and Development of Simulation System for Renewable Energy Laboratory, 2010 ASEEE Conference \& Exposition, June 20 - 23, Louisville, Kentucky (CD Proceedings).

22. D. J. Cornforth, A. Berry, and T. Moore, Building a microgrid laboratory, in Proc. 2011 IEEE 8th Int. Conf. Power Electron., and ECCE Asia (ICPE \& ECCE), 2011, pp. 2035-2042

23. S. S., Biswas, J. H. Kim, Student Member, A. K. Srivastava, Development of a Smart Grid Test Bed and Applications in PMU and PDC Testing, North American Power Symposium (NAPS), 2012, DOI: 10.1109/NAPS.2012.6336362

24. M.J. Stanovich, Srivastava, S.K., Cartes, D.A., Bevis, T.L., Multi-agent testbed for emerging power systems, 2013 IEEE Power and Energy Society General Meeting (PES), 2013, pp. 1 - 5, DOI: 10.1109/PESMG.2013.6672944

25. RTDS and RSCAD technical information. [Online]. Available: http://www.rtds.com/index/index.html

26. V. Salehi, A. Mohamed, A. Mazloomzadeh, and O. A. Mohammed, Laboratory-based smart power system, Part I: Design and system development, IEEE Trans. Smart Grid, vol. 3, no. 3, pp. 13941404, Sep. 2012.

27. V. Salehi, A. Mohamed, A. Mazloomzadeh, and O. A. Mohammed, Laboratory-based smart power system, Part II: control, monitoring, and protection, IEEE Trans. Smart Grid, vol. 3, no. 3, pp. 14051417, Sep. 2012. 